\title{
HOJAS UROLÓGICAS DEL DR. NARCISO SERRALLACH MAURI, ESCRITAS HACE CASI 100 AÑOS
}

\author{
Narcis Serrallach Milà, Francesc Serrallach Orejas' y Marc Serrallach Orejas.
}

Servicio de Urología. Hospital Universitario de Bellvitge. L'Hospitalet de Llobregat. Barcelona.

'Servicio de Urología. Hospital Sagrado del Sagrado Corazón. Barcelona. España.

\begin{abstract}
Resumen.- Se expone un resumen de los trabajos y comentarios más interesantes del Dr. Narciso Serrallach Mauri, presentados en Hojas Urológicas, revista que bajo su propia dirección editó de forma continuada desde 1913 hasta 1935, anual o semestralmente. En ella pueden encontrarse los temas urológicos que en aquel entonces eran de mayor actualidad y despertaban el mayor interés así como las publicaciones y actividades de las sociedades médicas donde desarrolló su actividad profesional urológica. Se hace hincapié también en la valoración de su actividad en relación al estado de la ciencia y de la sociedad en el periodo estudiado.
\end{abstract}

Palabras clave: Publicaciones Urológicas Españolas periódicas. Curriculum del Dr.Narciso Serrallach Mauri. Historia de la Urología Catalana y Española.

\begin{abstract}
Summary.- We present a summary of the most interesting works and commentaries by Dr. Narciso Serrallach Mauri, presented in Urological Records, a journal edited under his direction continuously from 1913 to 1935, annually or every six months. The state-of-the-art urological topics of the time rising the highest interest can be found in the journal, as well as in the publications and activities of the medical societies where he carried out his professional urological activity. We also emphasize the evaluation of his activity in relation to the estate of science and society at his time.
\end{abstract}

Keywords: History of urology in Spain. Periodic Spanish urological publications. Dr. Narciso Serrallach Mauri-curriculum vitae. History of Urology in Catalunya.

\section{INTRODUCCIÓN}

Hace tiempo, en 1992, cayó en nuestras manos, y merced a Laboratorios Morrith, una lámina que describía el Árbol Geneológico de la Medicina Española e Hispano Americana, realizada por el Prof. Antonio Orozco Acuaviva, Catedrático de Historia de la Medicina de Cádiz (Figura 1). Nos sorprendió primero y nos alegró después el encontrar en la rama Urológica del Arbol y entre las figuras más representativas el nombre de Narciso Serrallach Maurí, nuestro abuelo y bisabuelo. Todo y conocer el lugar que ocupó en la urología catalana, española (está referenciado en la Gran Enciclopedia Espasa) y por que no europea, pensamos que alguien, después de leer los trabajos que constan en su curriculum consideró que por el tiempo en que vivió y por los co- 
nocimientos de que disponía había conseguido una dimensión propia Esto nos tentó primero y nos obligó después a analizar su trayectoria profesional que se concretó en su extensa obra.

Al revisar los escritos exponentes de su trabajo destaca con claridad meridiana la necesidad de disponer de una publicación ("Hojas Urológicas") donde pudiera exponer los avances que había en el mundo de la urología y razonar y defender sus experiencias tanto en el campo doctrinal, experimental,como clínico. No por ello dejaba de poner su doctrina a la crítica de sus compañeros y a su vez expresar su desacuerdo en lo defendido por ellos, si se daba la ocasión. Ofrecía también revisiones muy personalizadas de los temas de actualidad, muchos de ellos de una frescura e intuición científica apasionante aún hoy, aunque siempre valorando el nivel de conocimientos que tenía la ciencia en general y la urología en particular entre el 1913 -1935. Las Notas Clínicas son de un realismo y fidelidad a la ciencia de la época. Informaba también la Revista de algunos eventos locales y de la Sociedad Catalana de Urología, de la Fundación y Sesiones científicas y administrativas de la Española y de los Congresos Internacionales, aportando resúmenes completos de los mismos. No faltan tampoco sentidas Necrológicas de su estimado maestro y de sus compañeros urólogos. Como colofón de lo expuesto anteriormente quisieramos transcribir el Prólogo de Presentación del primer número de "Hojas Urológicas" (Año I. Junio de 1913. n 1) y que tituló Nuestros Propósitos y que creemos define con exactitud su motivación fundacional (Figura 2).

Añadiremos también que a partir del número 13 de H.U. en 1927, mi padre y nuestro abuelo, F. Serrallach Juliá entró a colaborar en la redacción de la publicación.

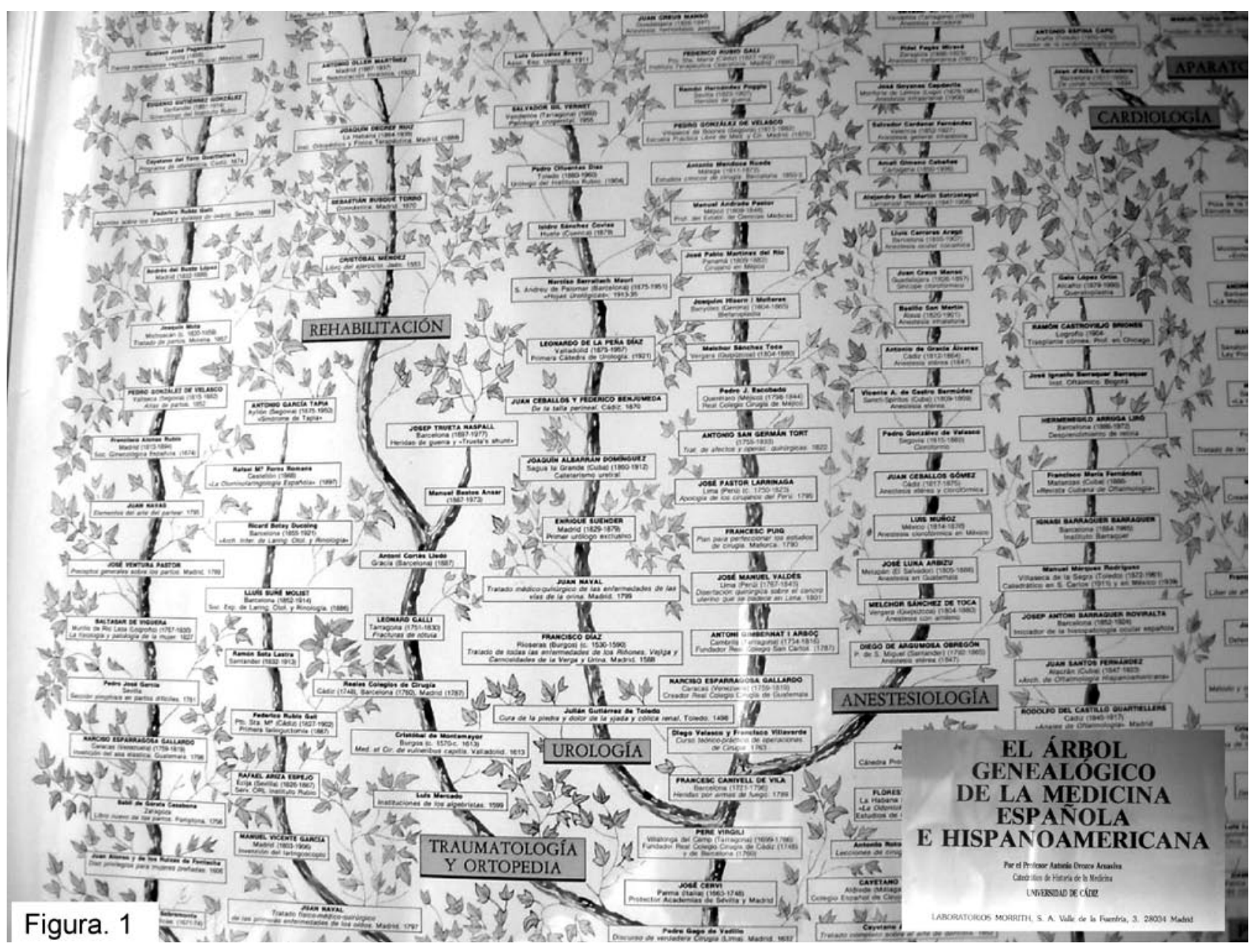

FIGURA 1. Árbol Geneológico de la Medicina Española y Hispanoamericana. Del Prof. Antonio Orozco Acuaviva. 1992 
Es nuestra opinión, que un hombre entregado a la ciencia, que mantiene una línea coherente y evolutiva del pensamiento sobre unos hechos determinados a los que dedica su mente, su trabajo clínico y experimental, su experiencia, su razonamiento y su tiempo, y lo refleja en el testimonio escrito de 22 años, el pensar que el Prof. Orozco valoró esta misma circunstancia. Posiblemente lo hicieron también los Drs. Insausti Cordón, Maganto Pavón y Pérez Albacete, entre otros, si leemos detenidamente la biografía que hicieron de él estos dos últimos autores en el contexto del libro sobre "La Historia Biográfica y Bibliográfica de la Urología Española en el siglo $X X^{\prime \prime}$ y que en el capítulo de la Urología Catalana realizaron (..A. Rousaud, J. Ponce de León, L. Gausa Gascón, M. Serrallach Orejas).

\section{Hojas Urológicas PUBLICADAS POR EL. Dr. N. Serrallach Aso I. Junio 1913 N. $\circ 1$}

\section{Nuestros propósitos}

Al publicar las Hojas Urológıcas, no pretendemos escribir una revista más, de las muchas que ya circulan; nuestros propósitos, se reducen por el momento, a coleccionar bajo una única enseña, el fruto de nuestros estudios de Urología clinica y experimental, que venimos ejecutando desde largo tiempo.

La labor de las Hojas Urológicas, será por el momento, personal; pues contamos con el suficiente material de estudio, para espiguear algo que pueda despertar el interés de la clase médica.

Nuestras numerosas publicaciones esparcidas entre folletos, revistas, boletines de academias, etc acerca de la fisio-patologia del aparato urosexual, pueden garantir nuestros plares y con más motivo, si afirmamamos que las Hojas UrológICAs, apareceran solo cuando se disponga de algo, que sea digno de ser sabido.

Es natural que dentro de estos límites, no nos concretaremos a exteriorizar los hechos originales y los de interpretación personal, que nos revele la observación y la experimentación, sinó a criticar sobre hechos, lo que de importancia, adquiera beligerancia en la ciencia urológica.

Si podemos lograr que las Hojas URológicas pierdan el caracter personal por aglutinarse a nuestro alrededor otros elementos más valiosos, nos daremos por muy satisfechos de haber fundado en España el primer periódico especial de Urología.

A toda la prensa profesional y política, ofrecemos nuestro modesto concurso y la más síncera salutación.

FIGURA 2. Hoja de "Presentación" de Hojas Urológicas, por el Dr. Narciso Serrallach Mauri. 1913.
No creemos sea de interés el repetir la biografía de D. Narciso Serrallach Maurí como uno de los protagonistas históricos de la Urología Catalana y Española muy bien definida, ordenada recopilada, entre otros por los autores citados anteriormente. Pero no debemos olvidar que la Historia de la Urología Catalana y Española se limita a unos cuantos nombres, sin menosprecio ni olvido de los que con su trabajo y dedicación enaltecieron y afianzaron la especialidad que hoy tenemos. Y la historia sólo recuerda la memoria escrita de los profesionales que la vivieron (publicaciones) aunque no olvida, pero de forma más suscinta, los hechos anecdóticos de la tradición oral.

\section{Puntualizaciones}

Antes de entrar en un análisis, controversia y valoración del contenido científico de "Hojas Urológicas" nuestro deseo es situar esta larga publicación de 22 años en tiempo real. La medicina siempre ha servido a la sociedad, y ésta, según su estado de desarrollo conceptual general y social ha tenido la medicina que necesitaba, merecía y podía.

Lo más apasionante, al valorar la vida profesional de cualquier hombre es el estudiar, medir y entender que los avances, intuiciones y descubrimientos siempre estarán dentro de los límites de los conocimientos de que disponían, de las vivencias del entorno y del momento de la sociedad en que vivían y de los profesionales con que convivian. Un claro ejemplo es la importancia que se da en "H.U" a las enfermedades venéreas. Formaban un cuerpo de doctrina profesional y social muy importante entre 1913-1935, pero después del descubrimiento y aplicación de las Sulfamidas (1932-34) y de la Penicilina (1940-45) cambió radicalmente.

Corresponden todos estos avances a que en la Ciencia y por tanto en la Medicina, desde Augusto Comte (1798-1857), se impone el positivismo. Después de las etapas Teológica y Metafísica de la Medicina se establece el Positivismo en el que el hombre renuncia a las verdades absolutas, al origen y destino del universo para dedicarse solamente a descubrir con la inteligencia, la razón y la observación sus leyes efectivas. Nacen y se desarrollan así las Ciencias Naturales, bajo el lema de Humanidad (Dios), Orden (Racionalismo Burgués) y Progreso. (de Lain Entralgo. Historia de la Medicina).

Breve Exposición y Comentarios del contenido de más interés de Hojas Urológicas (344 págs).

Como puede verse, en el Indice global de Hojas Urológicas (344 páginas) que transcribimos 
(Figura 3), su contenido está distribuido en capítulos conceptuales: Trabajos originales, Notas clínicas, Juicios críticos de la prensa médica, Aforismos en Urologia, Notas de Congresos y Reuniones de Sociedades y Necrológicas.

Hemos realizado un brevísimo resumen de los trabajos publicados en Hojas Urológicas. Hemos respetado y transcrito siempre lo escrito en el trabajo original. En ningún momento hemos introducido correcciones ni criterios de actualización.

\section{TRABAJOS ORIGINALES}

La prueba de los proteicos. N. Serrallach (Año 1 Junio 1913. n¹ pág. 2). "Ante la necesidad de disponer de una prueba para valorar el estado funcional de los riñones en sí o en cuanto a poder realizar una nefrectomía obligada sin temer una insuficiencia renal estudia y valora la fisio-patología del nitrógeno ureico. El régimen de proteicos es imprescindible junto con la Prueba del régimen glico-amiláceo (sin albuminas) para valorar la función renal a través del nivel de $\mathrm{N}$. ureico en sangre, su concentración en ori- na y el volumen de la diuresis, es decir para valorar la ureofiltración. Está de acuerdo con Legeau que las demás pruebas del azul de metileno, de la florizdina, índigo carmin,... deben pasar a la historia".

La producción de urea en los distintos régimenes alimenticios. N. Serrallach (Año 2. Mayo 1914. n־2. pag. 17). Estudia la Ureogénesis en pacientes con dieta Hipereazoada, Hipoazoada ○ Hidrocabonada. Termina el autor "Siempre que se quiera evitar o disminuir la degradación de la albúmina y sus efectos (acidosis, intoxicación humoral), el régimen hidrocarbonado cumplirá mejor que la dieta absoluta".

Lo que debe evitarse en la sífilis. N. Serrallach. (Año 2 Mayo 1914. no2. pag. 25)." No hay que esperar la evolución de la enfermedad. Hay que buscar el gérmen en el exudado superficial y si no en el raspado con cucharilla, pues el espirilo pálido, por ser anaerobio, siempre es más fácil sorprenderle en el parénquima de la neoplasia que en la superficie". Entre los muchos compuestos arsenicales de la terapéutica antiluética, existe una substancia, la Hectina - Antiluetina que al aplicarse por inyección alrededor del chancro a las 24 horas, éste entra en franca
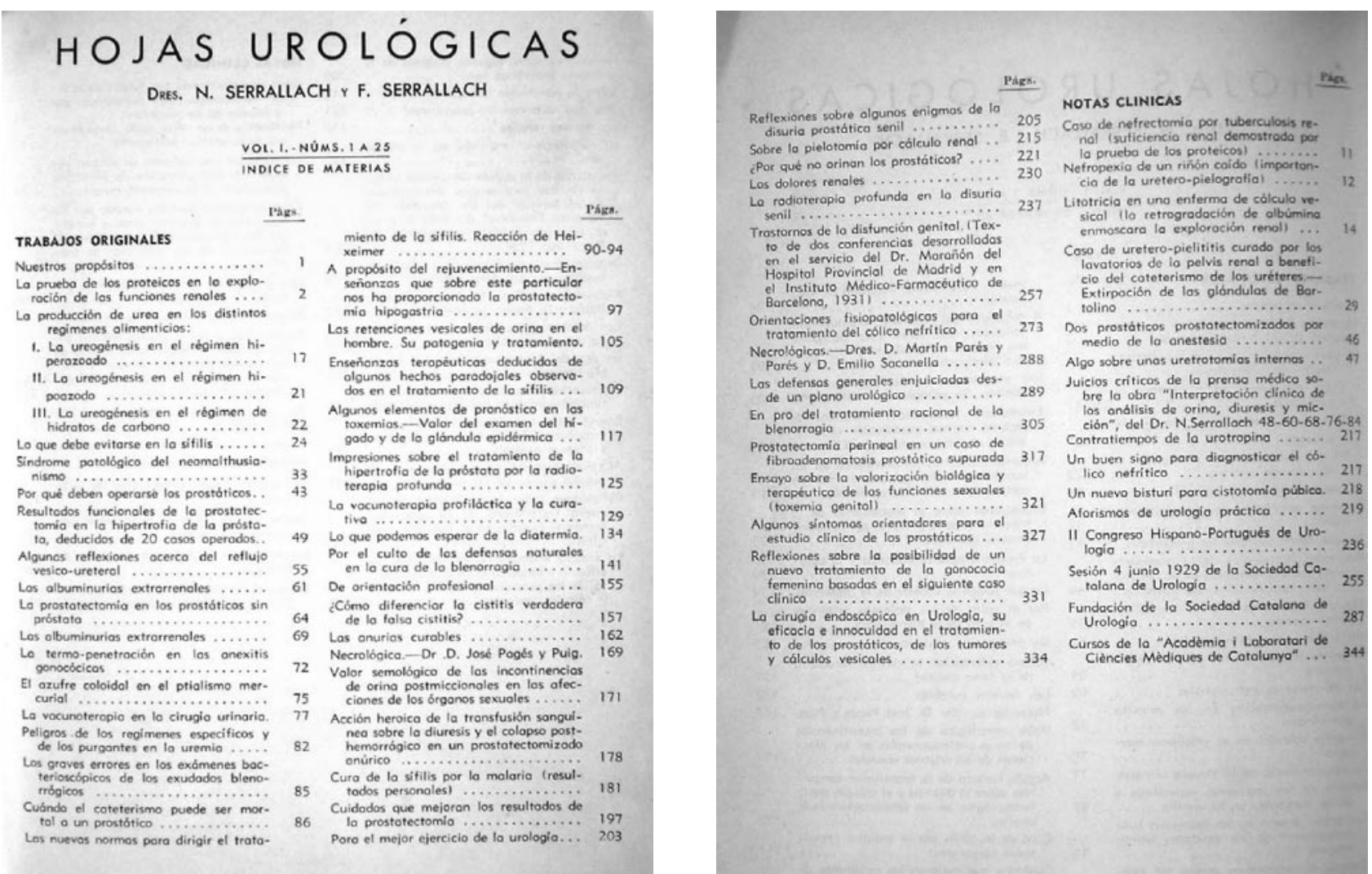

FIGURA 3. Hojas Urológicas. Índice de Materias. Números 1 al 15. 
cicatrización.; si no varía de morfología puede asegurarse que la lesión no es sifilítica. Tratado el chancro con hectina o extirpándolo con el ganglio satélite se aplicará el tratamiento sistémico que consiste en la administración de salvarsan o neosalvarsan a dosis pequeñas y repetidas. Si simultáneamente se administra el mercurio a grandes dosis y por via hipodérmica," es entonces cuando se empieza a creer firmemente en la curabilidad de la sífilis y aún en el tratamiento abortivo".

Sindrome patológico del neomalthusianismo. N. Serrallach. Año 3 . Octubre 1916. no3 Año 3. Octubre 1916. no3 (pag. 33)." El control de la procreación que defendió Malthus para hacer menos penosa a nuestros descendientes la lucha por la subsistencia obliga no sólo a la abstinencia sexual sino a realizar actos incompletos, masturbación e incluso excitaciones sexuales no seguidas de coito. Distingue el autor 3 fases en el acto genital completo: el congestivo, el secretorio y el liberativo o expulsivo. Cada fase comporta una situación orgánica, con clínica propia (orquialgia, varicocele, prurito anal,...), que de mantenerse puede abocar a alteraciones de la micción como el goteo postmiccional e incluso tenesmo, aparte de un estado hipocondríaco o una afección tóxica sobre la médula sacra. En los masturbadores crónicos puede llegarse a desarrollar una lesión patológica de tercer grado, con esclerosis, isquemia y acortamiento de la uretra posterior, causante de la clínica citada. En el perro se han conseguido reproducir esta lesiones. Tampoco la mujer queda exenta de los efectos de una relación sexual incompleta, ocasionándose dolores anexiales y trastornos del menstruo así como metritis, catarro cervical, ...y quizás, de manera más lejana, los quistes de ovario, fibromas,..."

Porqué deben operarse los prostáticos. N. Serrallach (Año 3 Octubre 1916. no3 pág. 43)." Después de los estudios anatomo-patológicos de Casper, Albarrán y Metz se dejó de sospechar que la retención vesical en la hipertrofia de la próstata no procedía de la parálisis vesical sino de la obstrucción y que extirpando la próstata se conseguía una micción espontánea (Dittel, Macías, González, Albarran y otros). No obstante las cifras de la mortalidad de la cirugía y de las complicaciones serias eran altas porque los urólogos no encontraban contraindicaciones".

Se comprendió que no todas las ocasiones eran propicias para extirpar la próstata. "No operamos ni debe operarse jamás un prostático intoxicado, antes es menester correr en auxilio del riñón agobiado, primero, modificando el régimen alimenticio en el sentido de hacerlo hipotóxico (vegetariano), y, segundo, drenando la vejiga por medio de la sonda permanente $o$ por cateterismos repetidos hasta que desaparezcan los fenómenos urémicos generales, y por último coadyuvando a la desintoxicación mediante purgantes y diaforéticos". También, según la experiencia del autor, hay que evitar la anestesia con Cloroformo lacción destructora sobre el epitelio renal) y la Raquianestesia (nucleolisis medular causante de parálisis en el postoperatorio). Concluye que con la anestesia local utilizando el método de Pagés e iniciando la enucleación prostática endouretral y por el pico, dejando intacta la vejiga, los resultados son muy buenos. Añade que en vista de ellos, no puede abandonarse un prostático a las graves consecuencias de la evolución espontánea de la hipertrofia".

Resultados funcionales de la prostatectomía en la hipertrofia de la próstata deducidos de $\mathbf{2 0}$ casos operados. N. Serrallach. (Año 4. Junio 1917. n4 pág. 49). Se ratifica el autor en todo lo citado anteriormente en relación a la cirugía de la próstata e insiste en la importancia de seleccionar y preparar al enfermo, al tipo de anestesia empleado y la técnica de enucleación practicada, siempre uretral, ya que de ello dependerán las complicaciones (hemorragias, fístulas, recidivas, infecciones, incontinencias, estenosis del cuello y celda). En dos pacientes hubo de practicarles el "ojal hipogástrico" hasta que se normalizó la azotemia y se corrigió la infección urinaria. "Con estos cuidados se logra salvar enfermos considerados como inoperables". El taponamiento de la celda prostática al que un día rendimos gran tributo hoy le acusamos de mantener un eretismo de la porción vésico-uretral y de facilitar la absorción de productos tóxicos que influyen muy desfavorablemente en el postoperatrio. Solo taponamos la celda prostática en casos de gran hemorragia y lo retiramos antes de 24 horas. Colocábamos en los primeros casos ademas del tubo hipogástrico una sonda uretral, pero la experiencia nos ha demostrado que la uretra debe permanecer libre para permitir los lavados abundantes y repetidos de la celda prostática. $Y$ tal es la aversión que sentimos por la sonda a permanencia que mantenemos el drenaje hipogástrico hasta que la herida ventral está apunto de epitelizarse". De los 20 pacientes "sólo 6 presentaron apatía sexual, pero dada la rehabilitación de los demás, cábenos la duda de si por verguenza ocultan su verdadera situación genital". En los demás, siempre se ha presentado el orgasmo, unas veces sin eyaculación; en estos casos no hemos podido averiguar si no existe o es retrógrada". Así la prostatectomía conserva el apetito sexual, la erección, el orgasmo, la eyaculación y en algunos casos es posible la virtud fecundante, a no ser la edad avanzada de los pacientes".

Algunas reflexiones sobre el reflujo vésico-ureteral. N. Serrallach (Año 4. Junio 1917. n4 pág. 55) "Cuando con el Dr. Pagés comunicamos a la Acadè- 
mia i Laboratori de Cièncias Mèdiques de Catalunya 3 casos de insuficiencia de la válvula vésico-ureteral, demostrada radiográficamente, nos formulamos una serie de consideraciones fisio-patológicas, que entendemos tienen gran importancia práctica". Después de los experimentos de Roswing y Albarrán los cultivos de gérmenes introducidos en la vejiga no podían infectar los riñones sino se producía una obstrucción uretral. La infección pielo-ureteral pues, sin patología vesical obstructiva, decían no podía ser más que de origen hematógeno. Sin embargo, había casos de nefrectomía en los que salía orina por la herida lumbar o que Pasteau, a la cistoscopia, veía una aspiración en el meato ureteral, después de la eyaculación o que una infección de la mucosa vesical-meatal se presentaba como un ectropion o aspecto vulvar del meato. Serrallach y Pagés al constatar por radiografías que el líquido inyectado en la vejiga en algunos casos subía al riñón por via ureteral sugirieron que una cistitis puede desarrollar por esta vía una infección en el riñón sano; o también que instilando substancias antisépticas en la vejiga y esperando su pleno llenado podía tratarse la infección de los riñones por la subida canalicular del antiséptico. El reflujo vésico-ureteral puede existir en el sistema urinario sano, concluyeron.

Las albuminurias extrarenales. N. Serrallach. (Año 5. Febrero 1918. n5 pág. 61 y Septiembre 1918 nº pág. 69). Al preguntarse porque unas nefritis cursan sin albuminurian surge el concepto de Albuminuria extrarrenal adquiriendo el riñón un doble comportamiento según la cantidad de ingesta, metabolismo de las albúminas y la actuación de los órganos que se encargan del mismo o de su destrucción. Si se inyecta al perro una dosis baja de ovoalbúmina, no aparece albuminuria. Si la dosis es alta ésta aparece en la orina. Se sugiere que si se sobrepasa una cantidad de albúmina superior a las potencias proteolíticas del organismo, aparece la compensación por el filtro renal, que es la albuminuria. Esto explicaría también la albuminuria de la fatiga al esfuerzo, causante de una mayor producción de albúminas heterólogas que las defensas proteolíticas del organismo es incapaz de desintoxicar." Que la alteración del parénquima renal es una causa de albuminuria nadie lo pone en duda, pero que las albúminas patológicas del medio circulante pueden atravesar la barrera renal y dar albuminuria, apellidada extrarenal, no son tantos los que lo abonan a pesar de las muchas pruebas aportadas".

La prostatectomía en los prostáticos sin próstata. $\mathrm{N}$. Serrallach. (Año 5. Febrero 1918. no5 pág. 64). La ausencia de lóbulos adenomatosos al tacto rectal en un retencionista contraindicaba la cirugía. Se consideraba que la problemática venía más por la paresia vesical que por el obstáculo cérvico-prostático. Sin embargo estos pacientes presentan fibroadenomas poco detectables yuxtacervicales y yuxta-uretrales que hacen inestensible y rígido el cuello vesical. La cirugía encuentra fuertes dificultades de penetración para la enucleación uretral, pero la liberación de ambas situaciones consiguen restablecer una micción fácil, espaciada y voluntaria. A estos prostáticos se les denomina sin próstata. La prostatectomía, en general, es tanto más benigna, cuanto antes se opere. "En este primer periodo los resultados son extraordinarios".

La termo-penetración en las anexitis gonocócicas. $\mathrm{N}$. Serrallach. (Año 5 . Septiembre 1918 no6 pág. 72) La acción curativa de la Diatemia se realiza a través del calor que se desprende en la parte del cuerpo interpuesta entre los dos electrodos de un generador eléctrico. Y que el gonococo por la acción del calor entre 40 y 50 grados sucumbe. Puede resultar peligrosa su aplicación en la fase aguda de las anexitis, por el peligro de difusión, secundario a la hiperemia del tratamiento, aunque con especial vigilancia, a dosis más bajas y repetidas, puede resultar beneficiosa. Sin embargo en las anexitis crónicas, donde todo fracasa, la termoterapia consigue resultados sorprendentes.

La vacunoterapia en la cirugia urinaria. N. Serrallach. (Año 6. Octubre 1919 no 7 pág. 77). "Una infección bacteriana depende tanto de la intensidad de la lesión anatómica como de las defensas del individuo. Un gérmen puede convivir en la uretra; si ésta se lesiona, puede producir una septicemia. Siguiendo los experimentos de Pasteur con el vibrión colérico, de Ferrán con la rabia y de Wright con cultivos de microbios, inyectándolos consiguieron artificialmente la formación de anticuerpos, inmunizando al individuo en general y especificamente para el gérmen inyectado. La guerra del 1914-18 es un exponente de ello (tifoidea, tétanos, estreptocacias, gangrena gaseosa...). Pero hay dos condicionantes: debe ser selectiva (del germen escogido) y sobre todo profiláctica. En estadios prodrómicos, de latencia o de proceso agudo puede ser letal al exacerbar el proceso. Es mejor las autovacunas que las stockvacunas. La recogida de muestras debe ser selectiva y meticulosa; se siembra en diferentes medios en cápsula de Petri. Las colonias, luego, se esterilizan; las vacunas para los aerobios a $60^{\circ}$. Los anaerobios se tratan a ebullición. Puede hacerse también por medios químicos. Su aplicación previa a la uretrotomía interna parece eficaz, sin poderlo afirmar como profilaxis a la prostatectomía y no hay experiencia en la infecciones altas."

Peligros de los regímenes específicos y de los purgantes en la uremia. N. Serrallach. (Año 6. Octubre 
1919 n 7 pág. 82). Atribuye el autor a la uremia el cambio lento de la osmosis sanguínea y a la acumulación de substancia tóxicas a nivel sanguíneo y sobre todo en las células de los parénquimas de los órganos de la economía. Así en las lesiones crónicas de compensación por lesiones renales, un purgante o una dieta severa puede producir cambios letales debidos al movimiento de tóxicos retenidos, al evacuar los existentes. (Se desconocía en aquel entonces el metabolismo y regulación humoral en la insuficiencia renal crónica de hoy).

Los graves errores en los exámenes bacterioscópicos de los exudados blenorrágicos. N. Serrallach. (Año 7. Octubre 1920, no 8 pág. 85)." Delante de un resultado bacteriológico negativo no hay que descartar la enfermedad investigada. Hay que ejecutar la búsqueda con pulcritud (frotis uretral escrupuloso) y disponer de un medio de cultivo seleccionado,como el suero humano y de una estufa de cultivo en el propio gabinete urológico. No se escapa la trascendencia social que tienen sus resultados".

Cuando el cateterismo puede ser mortal a un prostático. Prostatectomía en un retencionista con distensión de la vejiga. N. Serrallach. (Año 7. Octubre 1920, no 8 pág. 85)."Dos son los peligros de un retencionista crónico con insuficiencia renal ante nuestra actitud terapéutica: la evacuación de la orina y la consiguiente sepsis y la poliuria incontrolada. La evacuación vesical condiciona una hemorragia ex-vacuo, hágase lentamente, intermitente, con o sin sustitución de la orina evacuada con líquidos antisépticos. La sonda uretral a permanencia, entre otras complicaciones, comporta una lesión uretral que se añade a la vascular vesical que acaece a la evacuación y ambas abocan a un estado séptico. El ojal hipogástrico o talla vesical es la única solución que evita las complicaciones citadas, pero no la poliuria incontrolada, que según el autor elimina las toxinas circulantes y que da paso luego a las retenidas en los parénquimas. Recuperado el paciente, después de una delicada y peligrosa compensación, que precisa más de 6 semanas de drenaje, puede realizarse una prostatectomía con la técnica habitual y con las mismas garantias".

Nuevas normas para dirigir el tratamiento de la sifilis. Reacción de Herxheimer. N. Serrallach. (Año 7. Octubre 1920, no 8 pág. 90). (Año 8. Agosto 1921, no 9 pág. 93). En el tratamiento de la sífilis secundaria - terciaria," en los tejidos donde tiene lugar la fijación del antiluético al espirilo, se opera toda una serie de fenómenos reaccionarios que hoy conocemos como la reacción de Heixeimer (Obliteración parcial o total de las arterias afectadas con la consiguiente isquémia, hiperemia pasiva e incluso ulceración por gangrena, in situ, pero pueden, por la circulación trascender a otros órganos de la economía). Como antiluéticos el loduro y el mercurio tienen una dosis muy cerca a la tóxica y por lo tanto la reacción es más grave. Por el contrario los compuestos arsenicales orgánicos son 10 veces menor. Todo ello conlleva a dosificar menos dosis y fraccionarlas, empezando por el Salvarsán".

A propósito del rejuvenecimiento. Enseñanzas que sobre este particular nos ha proporcionado la prostatectomía Hipogástrica. N. Serrallach. (Año 8. Agosto 1921, nº 9 pág. 97)." Después de las pruebas aportadas por Steinach, Holznecht, Lichtstern, Hams, Lipchütz, Kreuter, etc... en pro del rejuvenecimiento no se puede dudar que se ha dado el primer paso para restituir las energias perdidas en la vejez prematura. Existe una relación entre hormonas genitales y caracteres sexuales secundarios (c.s.s.). La castración antes de la pubertad detiene el desarrollo de los órganos genitales. Si se realiza depués de la pubertad se detiene el desarrollo de los c.s.s. Se citan muchos experimentos en animales. "Sin hormona genital el organismo se intoxica, sus partes esenciales entran en degeneración grasa, el coeficiente de utilización de las albúminas baja, la fuerza muscular decrece y la inteligencia se embota, y por esto Brown Sequard dijo, por experiencia propia, que el extracto de testículo le había devuelto la energia perdida". Según Steinach las hormonas genitales se generan en los espacios intertubulares del testículo, situación que el autor sitúa en las células de los túbulos seminíferos. Basa lo dicho en que cualquier proceso tóxico sobre el testículo como el hambre, la avitaminosis, el frio, régimenes inadecuados 0 a la excesiva acción de la prostatina (nombre que da a una posible substancia hormonal segregada por la próstata) condiciona una atrofia del epitelio germinal y una congestión del tejido intersticial intertubular muy evidente. Es decir que las células de los túbulos seminíferos tienen una doble accíón secretora, interna-externa. "La pubertad se produciría en el momento en que el epitelio de los túbulos, en virtud de alguna otra hormona nacida quizás del tiroides - de la próstata, acarreada por la sangre experimenta una activación carioquinética que distiende las paredes de los tubos y cuyos productos de descamación se abren paso hacia el deferente no sin aplastar el tejido intersticial,que se devanece delante del predominio de los seminíferos; por esta causa el testículo se hace mayor y más blando". Describe dos observaciones: la toxemia genital en los vasectomizados y abstencionistas y, la $2^{\underline{a}}$, el rejuvenecimiento de los prostatectomizados al quedar el verdadero tejido prostático libre de la opresión de la hipertrofia y así poder segregar la prostatina que activará la actividad hormonal genital del testículo." 
Las retenciones vesicales de orina en el hombre. Su patogenia y tratamiento. N. Serrallach. (Año 10. Octubre 1922, n 11. pág. 105). Obra de 332 páginas con 128 grabados. Tanto para el urólogo como para el internista el conocimiento de la patogenia, el diagnóstico diferencial y el tratamiento de las retenciones de orina se expone ordenadamente, desgranando en XV capítulos, desde la anatomía y fisiología hasta la exploración del retencionista y de las técnicas de sondaje, anestesia en urología y el tratamiento quirúrgico. "Todo un completo y actual tratado de los años 1922."

Impresiones sobre el tratamiento de la hipertrofia prostática por la radioterapia profunda. N. Serrallach. (Año 10. Agosto 1923 n 11. pág. 125). "La radioterapia profunda es un medio terapéutico que nos tiene reservadas grandes sorpresas y aunque algunas de ellas han de redundar en beneficio de la humanidad, se vislumbran ya algunas otras que invitan a una serena reflexión, mayormente cuando la electrotécnia en su vertiginoso progreso y con el fin de satisfacer los deseos de la clínica proporciona al radiólogo aparatos de voltaje cada vez más altos, pero que a cambio de proporcionar un mayor rendimiento terapéutico también son de más difícil peligroso manejo. El tratamiento de la hipertrofia prostática por los rayos $\mathrm{X}$ además de los peligros generales a toda irradiación, tiene otros particulares a dicha dolencia que pueden cerrar definitivamente a los enfermos toda esperanza de curación pero disponiendo como disponemos actualmente de la prostatectomía podemos ofrecerles felizmente su añorada salud. La radioterapia se limitaria, de momento, a las disurias de fondo congestivo, con precaución y prudencia".

La vacunoterapia profiláctica y la curativa. N. Serrallach. (Año 11. Mayo 1924 n 12. pág. 129) "Es tal la confianza que tenemos en la vacunación preventiva que después de una uretrotomía interna, salvo la amenaza de hemorragia, jamás ponemos sonda a permanencia; sin embargo en el postoperatorio continuamos poniendo vacunas, pues diríase que los anticuerpos acumulados previamente van gastándose hasta el momento que se agotan, que es cuando estallan las complicaciones". "Con Vives encontramos que la reagudización de una gonococia coincidía con una bajada de las aglutininas específicas de la sangre. La técnica es importante para los resultados. La inyección debe ser intradérmica, múltiple y en áreas de poca circulación linfática: deben pasar las heteroalbúminas por el filtro de la piel. La vía hipodérmica es más peligrosa por la posibilidad de una rápida absorción circulatoria que puede agravar tóxicamente los órganos nobles. Igual se ha visto con la vía peritoneal en el perro. Parece que hoy se tien- de a unificar el concepto de actuación de las vacunas con el de las proteínas. Ambas actúan consiguiendo una crisis hemoclástica, pero jamás con las proteínas hemos conseguido los efectos terapéuticos que con las vacunas y que preferimos confeccionarlas con el mismo gérmen responsable en el terreno patológico. Aconsejamos una fórmula de la casa FHER, de Barcelona, que contiene los gérmenes que más corrientemente se encuentran en las vías urinarias normales y patológicas y que se dosifican por millones por cc."

Lo que podemos esperar de la diatermia. N. Serrallach. (Año 11. Mayo 1924. no 12. pág. 134). "Creemos que la diatermia no debe reducirse a la aplicación empírica de las corrientes termógenas sobre los focos gonocócicos, como todavía pretenden muchos y se creyó desde sus principios, con el ánimo de destruirlos térmicamente, sino que este medio terapéutico está indicado en todos aquellos procesos, sean o no microbianos, que necesitan una influencia vasodilatadora, cuando les es conveniente un aflujo leucocitósico y siempre que los tejidos necesiten un estímulo en sus intercambios nutritivos. Las indicaciones se extienden sobre todo a capítulos más vastos que la Urología y en especial a procesos crónicos de naturaleza vascular o diatésica". "Las indicaciones urológicas serían las uretritis blenorrágicas, las litritis cerradas, las induraciones uretrales, la prostatitis y las vesiculitis; en las epididimitis en periodo de declinación la diatermia favorece la permeabilización de las espermáticas. No menos elogios merece el tratamiento de las anexitis crónicas en la mujer."

Por el culto de las defensas naturales en la cura de la blenorragia. N. Serrallach. (Año 11. Octubre 1924, $\mathrm{n}^{\circ} 13$. pág. 141). "El pesimismo que reina sobre el tratamiento de la gonococia, procede menos de nuestra impotencia curativa que del uso inadecuado e intempestivo de los recursos terapéuticos y para evitarlo intentaremos dar a cada cosa su valor y a cada método su posición. La suerte de un blenorrágico puede mejorarse fomentando las defensas locales (integridad epitelio uretral y de su vascularización, control excreción urinaria de tóxicos e irritantes, control acidez urinaria, fomento defensas locales-baños, cataplasmas, diatermia, vacunas...) y generales del organismo; esgrimiendo oportunamente los agentes terapéuticos $y$, por fin, coordinando ambas sin perjuicio para ninguna de las dos".

De orientación profesional. N. Serrallach. (Año 11. Octubre 1924, no 13 . pág. 155). "Los médicos que se especializan cuando conocen a fondo los grandes procesos biológicos, capacitados para interpretar los más complicados problemas clínicos. Las grandes diferencias fisiológicas que apreciamos en los distintos órganos de la economía dimanan de funciones que 
son comunes y fundamentales a toda la gran familia celular, y gracias a este parentesco y a esos lazos de mutualidad, surgen analogías entre los cuadros nosológicos de los diversos sistemas celulares y los grandes factores morbosos actuan en todos los tejidos, por lo que veremos a unos mismos principios terapéuticos encontrar afortunada indicación en varias afecciones". La formación completa del profesional le orienta en el juicio diagnóstico, en la aplicación de la moderna tecnología de que dispone y en estudiar las reacciones que aparecen a una terapéutica y esta orientación debe ser aplicable a cualquier especialidad".

\section{¿Cómo diferenciar las cistitis verdadera de la falsa} cistitis? N. Serrallach. (Año 12. Junio 1925, no 14. pág. 159). Se estudia la anatomofisiología del riñón y de la vejiga y de su relación en cuanto a la infección, de su inervación y del porqué del dolor. La expresión clínica de la vejiga puede ser consecuencia de su alteración o de la de su vecindad. Así puede hablarse de cistitis verdaderas y de falsas. "Ya Guyon en sus tiempos, convencido del gran número de falsas cistitis, creyó oportuno lanzar la voz de alarma, y con su autoridad proclamó que para poder afirmar el diagnóstico de cistitis era preciso la asistencia de piuria, hematuria terminal y polaquiuria dolorosa." $Y$ puede sintetizarse simplemente en el diagnóstico de las polaquiurias que: "La cistitis protopática aparece con una perfecta concordancia entre la capacidad vesical y la cantidad de orina emitida por micción; en la cistitis falsa, aparece un gran contraste entre una y otra cifra. $Y$ es necesario que nadie lo olvide, para que acabe para siempre la historia de las cistitis tuberculosas y se yugulen las tan sonadas cistitis rebeldes".

Las anurias curables. N. Serrallach. (Año 12. junio 1925. nำ 14 . pág. 162). "La anuria revela indudablemente la claudicación de la célula renal. A estas se la llama secretoras. Las excretoras obedecen siempre a causas obstructivas y por lo tanto corregibles. "La anurias secretoras se clasifican en incurables cuando corresponden a la degeneración crónica de los riñónes. Las curables son consecuencia de una lesión transitoria del filtro renal y en las que la experiencia nos ha enseñado que los auxilios quirúrgicos pueden devolver al riñón sus facultades perdidas". Las incurables o Brightianas cursan con azotemias no muy altas en su periodo final. En las curables, la urea en sangre puede alcanzar cifras fantásticas, que lejos de ser de mal aguero son esperanza de una indicación quirúrgica (capsulotomía renal o nefrotomía) si no obedecen farmacológicamente... Entre las anurias curables está el grupo de las excretoras, determinadas por obstáculos mecánicos altos y que no necesita ser bilateral. Este fenómeno quiso explicárselo Guyón por el reflejo reno-renal; pero esto no dió la más pequeña luz acerca de sus causas eficientes y seguimos como entonces ignorando el proceso en todos sus aspectos". Las anurias bajas son retenciones de orina y han sido expuestas en otros trabajos nuestros.

Valor semiológico de las incontinencias de orina postmiccionales en las afecciones genitales. N. Serrallach. (Año 13 Marzo 1926. n 15. pág. 171) "Distinguimos dos grupos de incontinencias de orina postmiccional. El primero aparece cuando la uretra no se plica después de la micción y vacía después la orina residual uretral por debajo del esfintrer externo en forma de goteo. La expresión uretral evacúa algo de orina. Cualquier patología que estenose o dé rigidez a la uretra es capaz de producirlo. El segundo grupo es patognomónico de los estados congestivos y especialmente de la plétora de los receptáculos espermáticos, cosa que no se encuentra consignada en ninguna parte todavía y que nosotros somos los primeros a describir y a recomendar como un signo genital de gran valor diagnóstico. Consistiría en un proceso activo de contracción de la uretra prostática y otro de pasivo de relajación del esfinter externo, con la consiguiente salida de orina que empuja la uretra posterior." Expone el autor una explicación en la que intervienen mecanismos anatómicos, hormonales y nerviosas, como condicionantes de la congestión prostática, especialmente como consecuencia de las situaciones hipersimpáticotónicas que engendra el ejercicio anómalo de las funciones sexuales (falsos coitos, masturbación, continencia forzada,...).

Cura de la sifilis por la malaria "Resultados personales". N. Serrallach y F. Serrallach Julia. (Año 14 Marzo 1927. no 16 pág. 181) Trabajo muy completo pero de interés histórico solo. Describe los resultados, muy buenos en aquel entonces, "aplicando los consejos de Kyrle, que recomienda acompañar la fiebreterapia (piroterapia) a una medicación específi$\mathrm{ca}$, pues una y otra terapia se complementan, ya que donde termina o fracasa la eficacia de los antiluéticos comienza la de los palúdicos."

Cuidados que mejoran los resultados de la prostatectomía. N. Serrallach. (Año 14 Marzo 1927. n 16. pág. 197)" No sólo la selección de los pacientes y una buena técnica quirúrgica son importantes sino también unos buenos cuidados postoperatorios. Así es importante que los pacientes sean delgados, estén en situación de régimen hidrocarbonado previo, compensados cardiológicamente, con protección infecciosa con vacunas. Como preparación de los retencionistas no infectados preferimos la cistostomía a la sonda. A los infectados, con orinas fétidas, preferimos los cateterismos intermitentes y de algún lavado con soluciones coloidales de plata (colargol, 
protalgol,..), no olvidando el gargarismo (?) de la uretra posterior, lugar habitual de la infección. Antes de la intervención adrenalizamos al enfermo, como poderoso impulso que imprime a las energias latentes el principio activo suprarrenal, sobre todo cuando se simultánea con la digital. Se administra sales de calcio y coaguleno para asegurar la hemostasia. La prostatectomía se realiza en dos tiempos, habitualmente, y separados por 2 o 3 semanas. Somos partidarios de la ligadura de los deferentes, a la que atribuimos una acción protectora de la epididimitis y un estímulo de la hormona genital con su acción tónica. La mejor anestesia es la local para la cistostomía, evitando su entrada en la cavidad peritoneal. Para la prostatectomía, completamos la anestesia con la instilación de la vejiga con una solución de novocaína con adrenalina al $6 \%$ previa inyección de morfina vía general. No infiltramos los tejidos periprostáticos por complicaciones peligrosas; con unas inhalaciones de cloroformo, eter o cloruro de etilo puede potenciarse la anestesia en el momento de la prostatectomía. Siempre utilizamos la enucleación endouretral. Ante una hemorragia inquietante debe practicarse un taponamiento que se retirará a las 24 horas. Hay que valorar la vasoconstricción previa de la adrenalina ante una hemorragia posterior. Dejamos sonda de Pezzer hipogástrica con reducción progresiva del calibre para retirarla a los 5 8 días colocando un colector hipogástrico de lving. El paciente se levanta alos 5 días. La hemorragia en el postoperatorio obliga al tratamiento con coaguleno, ergotamina, hemostil y un buen taponamiento si es preciso. La transfusión sanguínea en cierto momento nos salvó un caso desesperado".

Para el mejor ejercicio de la Urología. N. Serrallach (Año 14 Marzo 1927. nำ16 . pág. 203). "La práctica de la Urología Moderna, dado el abundante material terapéutico y múltiples medios de exploración que hoy se dispone es dificil de llevarla a cabo en un gabinete de consulta sencillo. Desde que por haber vivido los inconvenientes mentados reunimos bajo un mismo techo: el laboratorio químico, bacterológico y fotográfico; el gabinete radiológico (Rayos $X$ y radioterapia), el instrumental endoscópico y cruento, las salas de exploración y operatorias y un servicio de camas para residenciar a los enfermos operados o en curso de exploración,además del personal facultativo y subalterno especializado, nuestra labor diagnóstica y terapéutica ha mejorado extraordinariamente; y no podía suceder de otra manera, ya que nuestros enfermos han recibido a toda hora y a cada momento la asistencia que requería su situación clínica".

Reflexiones sobre algunos enigmas de la disuria prostática senil. N. Serrallach (Año 14 Diciembre 1927. $\mathrm{n}^{\circ}$ 17. pág. 205). Confirma este trabajo lo expuesto con anterioridad que resumido puede concretarse en que existen prostáticos con hiperplasia, otros con hipoplasia y otro grupo que presentan un amplio proceso de hipotrofia que conduce a los órganos que integran la uretra posterior a la más grande regresión morfológica y funcional que los autores relacionan, con trabajos experimentales, a la involución senil del testículo sobre la próstata. En estos pacientes la próstata se vuelve pequeña, enjuta y dura; la uretra corta, estrecha y rígida; y el cuello inmóvil, en trismus y escleroso, es indudable que la degeneración fibrosa de la zona uretro-prostática puede atribuirse a un hecho de regresión general, pero en algunas ocasiones creemos con Bartrina que puede ser el preludio de una degeneración maligna y quién sabe si su origen es debido a la fibrosis de la involución senil. Igual proceso puede acaecer en la mujer y que se denomina prostatismo femenino y obedece a las mismas causas y se encuentra lesiones parecidas del aparato urinario bajo, además del genital propio".

Un nuevo bisturí para la cistostomía: el Bisturí Arpón Serrallach. N. Serrallach. (Año 14 Diciembre 1927. nº 17. pág. 218). Estudiado para facilitar las cistostomias. Fabricado, según indicaciones del autor por la casa Drapier de Paris, ha tenido una difusión mundial.

¿Porqué no orinan los prostáticos?. N. Serrallach (Año 15 Octubre 1928. no 18. pág. 221). La hipertrofia prostática no obliga necesariamente a la disuria. Precisa del concurso de otras circunstancias para condicionar una retención y según sean éstas será definitiva o transitoria. "Según Young, Wesson, Macht, Denningt y otros han demostrado con pruebas embriológicas, anatómicas, fisiológicas y farmacodinámicas la existencia en la región vesico-prostática de dos sistemas musculares antagónicos: el trigonal y el esfinteriano que hacen de la continencia y de la micción dos procesos absolutamente activos, en virtud de los cuales el acto de orinar resulta de haber vencido los músculos trigonales a los del cuello,y viceversa en la retención". El autor hace una descripción anatómica del sistema aportando datos de comprobación endoscópica. "Como causas de retención definitiva están la retracción fibrosa del cuello vesical y de la uretra posterior, proceso que cuando no es neoplásico a nuestro entender resulta de la involución genital senil. La adeno-fibro-miomatosis es capaz también de atrofiar, de hacer ineficaces las contracciones del músculo de Bell, porque empujando las masas esferoidales hacia la sínfisis pubiana, estas se incrustan y fijan el cuello vesical, fibroso e inextensible. Las causas de la retención transitoria actuan de la misma manera, pero la rigidez del cuello y uretra posterior se produce por medios inflamatorios y por lo tanto reversibles a cualquier método que consiga reabsorber estos exudados". 
Los dolores renales. N. Serrallach y F. Serrallach Juliá (Año 15 Octubre 1928. no 18 pág. 230). "Cuatro factores despiertan la sensibilidad renal de una manera precisa y peculiar a cada uno de sus orígenes. Son: 1) la tracción con estiramiento de los nervios del pedículo renal; 2) Aumento brusco de la tensión intracapsular; 3) Dificultad en el desague de la pelvis renal; $y$ actuación de una perinefritis". $Y$ hacen una exposición detallada, extensa y muy clínica de cada situación patológica.

La radioterapia profunda en la disuria senil. N. Serrallach y F. Serrallach Juliá. (Año 16 Octubre 1929. nº 19. pág. 237). Pocas cuestiones hay más debatidas que la radioterapia profunda (R.P.) en la disuria senil. Hacen los autores una detallada exposición sobre la radioterapia (R.) y sus aplicaciones en urología. Lo exponen en varios capítulos que son: Razones que abonan la confusión que hoy reina sobre los efectos de la R.P. en el prostatismo; Consecuencias de haber querido relacionar las impresiones del tacto rectal con la naturaleza histológica de los esferoides; Análisis de algunos resultados de la R.P. en los prostáticos; Examen del proceso biológico que gira alrededor de la R. en los prostáticos; Estudio comparativo entre el proceso que engendra la disuria senil y la acción biológica de los rayos $X$; Indicaciones de la R.; Técnica de la R. (La tesis que presentó F. Serrallach Juliá para doctorarse versó sobre La Radioterapia Profunda en el Tratamiento de la Hipertrofia de la Próstata).

Trastornos de la disfunción genital. Continencia, neo- maltusianismo y masturbación. N. Serrallach. Conferencia desarrolladas en el Servicio del Dr. Marañón del Hospital Provincial de Madrid y en el Instituto Médico-Farmacéutico de Barcelona (Año 17 Octubre 1930. no 20 . pág. 257. (Texto de las dos conferencias)."El capítulo de las funciones sexuales es de los que necesitan una profunda revisión porque infinidad de principios fisiológicos clásicos no bastan a explicar la serie de manifestaciones de orden patológico que tenemos a la orden del día". Lo desarrolla en los siguientes apartados: Condiciones que motivan la actividad de las glándulas espermáticas; cambios que experimenta el esperma retenida; retención espermática aguda; retención espermática crónica y sindrome de la retención espermática crónica.

Afirma el autor que" la abstención sexual por no permitir entrar en funciones a un aparato que reside para algo en nuestro cuerpo, deja de explotar un capital energético de gran influencia sobre todas las actividades orgánicas y que sólo despierta y fomenta el ejercicio de las funciones sexuales. La abstinencia sexual es racionalmente anormal, y nunca podrá ser defendida por los higienistas. La continencia conduce a la retención de productos tóxicos de la espema retenida cuya reabsorción condiciona alteraciones del equilibrio orgánico, causantes de un sinfin de lesiones locales y trastornos generales que perturban la salud".

Orientaciones fisiopatológicas para el tratamiento del cólico nefrítico. N. Serrallach y F. Serrallach (junior) (Año 18 Noviembre 1931. no 21 pág. 287). El cólico nefrítico es una demostración subjetiva del hiperperistaltismo y de la contractura dolorosa del músculo liso que integra las paredes del embudo pieloureteral, pero en gracia a sus varias localizaciones y a sus diversas intensidades también ostenta una sintomatología que podríamos agrupar en tres cuadros clínicos: el superior (dolor en triángulo lumbar con o sin irradiaciones esplácnicas) el inferior (tenesmo vesical, rectal, dolor en testículo y glande,..) y el mixto". Estudia después la anatomofisiologia de las vías altas y bajas, con especial mención a su inervación sensitiva y dolorosa y a la transmisión de la onda ureteral que se interrumpe en las lesiones y suturas transversales del ureter. Otra observación es la de que el dolor desaparece no por desaparecer la obstrucción sino porque cede la formación de orina, por ello los diuréticos estarán contraindicados." $\mathrm{Si}$ se administran diuréticos a un cólico que cursa con anúria, al reemprenderse la diuresis puede haber una poliuria tan intensa de desintoxicación que puede ser letal para el enfermo" ¿Qué pauta debe aconsejarse? Combatir el espasmo y la diuresis, alternando los sedantes, los antiespasmódicos y el régimen seco con los frenadores de la secreción renal. El diagnóstico se hará por radiografia simple, pielografía descendente con Abrodil o Uroselectan como información morfológia. La litiasis úrica es radiotransparente. De no existir una expulsión espontánea si se trata de una litiasis, el paso siguiente será el cateterismo, asociado, si es preciso, a una pielografía ascendente que puede informarnos además de acodaduras o estenosis ureterales. La extracción endoscópica del cálculo con la sonda rastrillo de Genoville no siempre es posible. La cirugía es la última solución sea extirpando el cálculo, pexiando el riñón o corrigiendo una periureteritis".

Las defensas generales enjuiciadas desde un plano urológico. La hiperfilaxia, la hipofilaxia y la isofilaxia.Orientaciones terapéuticas. N. Serrallach. (Año 19 Enero 1933. no 22. pág. 289). (extracto del discurso inaugural leído en la "Academia i Laboratori de Ciencies Mèdiques de Catalunya" el 12 de Octubre de 1932. Inicia el discurso así: "Primer acto que nuestra asociación celebra en el "Casal del Metge", o sea en esa mansión fraternal que a todos nos cobija y atrae porque la integran y sostienen pedazos de nuestro corazón y aromas de nuestro espíritu desprendidos de la fragua de una vida de trabajo y de sufrimientos. Vamos a hacer un repaso sobre la 
actuación de las defensas del como nos lo enseñaron nuestros maestros, pero localizándolas bajo las enseñanzas de nuestra experiencia, iluminada por los descubrimientos de la biología moderna y con el propósito de edificar la verdad de hoy, pero sin lo pretensión que sea del mañana." Después de un repaso histórico de hechos y personas de la medicina que estudiaron las defensas generales del organismo en relación a la agresión nosológica concluye: "Afirmamos que los médicos, para ejercer el arte de curar, deben hacer una afinada crítica del camino y marcha que toma el organismo en la lucha contra la enfermedad para ayudarle cuando convenga o frenarlo cuando sea preciso. Tanto en uno como en otro caso, es indispensable regirse tomando por norma los principios orientadores de los grandes procesos de la defensa normal (isofilaxia) que es lo que hemos aprendido en la obra científica de nuestro maestro el Profesor Dr. Freixas y Freixas".

En pro del tratamiento racional de la blenorragia. N. Serrallach. (Año 20 Enero 1934. no 23 . pág. 305.)" No debemos esperarlo todo de la acción microbicida directa de los medicamentos, sino a otra índole de actuación favorable a la defensa orgánica cuyos beneficios se extienden a distancia. Tenemos en el proceso gonocócico uretral dos actuaciones: la obra directa del gono y la indirecta producida por los tóxicos celulares. Esta última para nosotros tiene más trascendencia que la primera porque el curso de la infección está menos subordinada a la virulencia del gérmen que al número de leucocitos que acuden y a su fragilidad. Así nuestra actuación en el estadio agudo de la blenorragia consistirá en disminuir la leucolisis y la diapedesis." Estudia luego los mecanismos aducidos y los métodos aplicados para su consecución y establece que tambien deben valorarse los otros blenorrágicos, en los que su organismo se defiende menos. Finalmente valora la piroterapia como movilizar de defensas en las zonas enfermas.

Algunos síntomas orientadores para el estudio clínico de los prostáticos. N. Serrallach (Año 20 Noviembre 1934. n 24. pág. 321). "Los prostáticos que no mejoran con los sondajes ni con los antisépticos y que la radiografía y la endoscopia no son aclaratorias podemos asegurar que sufren de cálculos, de divertículos, de infecciones, de neoplasia de vejiga o próstata 0 lóbulo medio de gran espolón vesical. A pesar de los fracasos exploratorios cuando el prostático no encuentra alivio a sus dolencias, aún sin tener el diagnóstico, debe operarsele abriendo la vejiga y buscar las patologías citadas anteriormente. De no intervenirse, corre el riesgo de una certera y letal complicación".

La cirugia endoscópica en urología. Su eficacia e inoquidad en el tratamiento de los prostáticos, de los tumores y cálculos vesicales, de los cuerpos extraños de la vejiga y del ureter y en la cura de la pielonefritis. N. Serrallach y F. Serrallach Juliá. (Año 21 Noviembre 1935. no 25 . pág. 333). "La urología, gracias al invento de Nitze, el cistoscopio, tuvo en manos del profesional la posibilidad de ver y explorar las vías urinarias bajas, para permitir después el cateterismo de los riñones através de ureter, para últimamente poder tratar muchas afecciones sin aplicar los métodos cruentos habituales. La resección endoscópica del cuello vesical en la hipertrofia prostática puede resolver la causa del porque no orinan los prostáticos: la esclerosis del cuello vesical. Basta una resección o incisión posterior profunda del cuello en los prostáticos sin próstata. Las autores llevan cuatro años de experiencia, que publicaron en la Revista Española de Urología a pesar de no disponer mas que del cauterio frío (electrocoagulación) que tiene el inconveniente de provocar hemorragia al eliminarse la escara. A pesar de ello defienden su eficacia. Presenta varios casos clínicos con excelente resultado. No obstante el futuro está en la justa combinación de las ondas entretenidas y las amortiguadas; unas cortan y las otras coagulan y así se evita el problema del salto de la escara. Otra aplicación es la electrocoagulación de los tumores vesicales no infiltrantes. Los resultados, si se eligen los pacientes es bueno. Igual resultado se consigue con la extracción de los cuerpos extraños de la vejiga. El tratamiento de los cálculos ureterales mediante el caterismo ureteral drena y ensancha el conducto y muy amenudo con la retirada de la sonda se expulsa el cálculo. También permite el cateterismo el tratamiento (lavados desinfectantes) de las pielonefritis, en especial en las hidronefrosis infectadas de las gravídicas."

"Este nuevo arte de curar ha entrado definitiva y triunfalmente en uso y que será para los tiempos futuros la enseña con que se distiguirá nuestra época en la historia de la medicina: La época de la escopia, o sea la cuna de uno de los mayores prodigios del ingenio humano."

\section{NOTA CLÍNICA}

- Un caso de nefrectomía por tuberculosis renal (Año 1. Junio 1913. no1 pág. 11) en el que se demostró la suficiencia renal previa por la prueba de los proteicos, que el postoperatorio confirmó.

- Un $2^{\circ}$ caso de dolores en región renal izquierda y que por uretrero-pielografía retrógrada con Colargol $4 \%$ se diagnosticó una pieloectasia por ectopia renal (no habla de nefroptosis) y que solucionó una nefropexia. 
- El último caso informa de una enferma con clínica de cistitis aguda florida, hipertensión vascular y trastornos gastrointestinales. Se pensó en patologia renal. Se descubrió una litiasis vesical y la prueba de los proteícos descartó insuficiencia renal. Practicada la litotricia la paciente fué dada de alta a los 3 dias. Comenta el autor que esta operación era de sobras olvidada en nuestro pais, pues apenas se publican casos.

- Paciente de 31 años con cistitis y pielonefrritis recidivante (Año 2. Mayo 1914. n². pág. 29). Después de un tratamiento que la enferma no supo especificar, volvieron el dolor lumbar derecho, especialmente en bipedestación y que cedía al reposo. Micción frecuente, orina turbia y a veces hemática. Leucorrea, vulvitis, con infección por gonococo en las glándulas de Skene y Bartolino Se realizaron 6 sesiones, 1 cada 8 días de una solución de nitrato de plata al 2-3-4 por mil. en pelvis renal y uréter,consiguéndose la desaparición de las molestias. Tratada la infección cedieron los dolores lumbares derecho secundarios a la ectopia renal (Ptosis). Sin embargo unos días más tarde recidivaron las molestias y se apreció que la infección vulvar, desatendida había recidivado y se localizaba en las glándulas de Bartolino, que extirpadas curaron a la enferma. Hace el autor 2 consideraciones sobre este caso clínico: La ectopia renal y la Cistitis. La ectopia renal (no habla de Ptosis) si no hay anomalías vasculares o patología que endurece y fije el ureter no habra obstrucción al descender el riñón. "No deben seccionarse los vasos polares renales porqué son terminales y condicionaran un infarto renal, como hemos observado en experimentos de trasplantación renal y en la práctica". La cistitis no siempre es una patología vesical. Puede ser un reflejo de una infección renal. El diagnóstico se realiza especialmente porque en el síndrome reflejo, la capacidad vesical al inyectar líquido se mantiene aunque se mantiene la frecuencia de las micciones, cosa que no sucede con las cistitis infecciosa baja.

- Dos pacientes prostatectomizados por medio de la anestesia local (Año 3. Octubre 1916. n³ . pág.46) evita la acción tóxica del cloroformo, recordando que la enucleación endouretral de la próstata, incluso del lóbulo medio, preserva la mucosa vesical, que lesiona la técnica de Freyer, evitando las complicaciones citadas anteriormente.

- A un paciente con mal estado general, con orinas muy piuricas cuyo diagnóstico oscilaba entre una litiasis y una tuberculosis se le practicó una nefrectomía, después de conocer por el cateterismo ureteral de ambos riñones y la prueba de los proteicos que el riñón contralateral era suficiente, como demostró el postoperatorio.
- Sobre la uretrotomía interna opina: la mejor incisión no debe ser única y sobre la pared superior de la uretra, sino radiada. No provocan más hemorragia y retardan la recidiva. Debe dilatarse la estrechez después de la dilatación mejor con sondas metálicas. Las mejores sondas son las bequilladas y en orinas transparentes y riñones íntegros no colocamos sonda. Esta se indicará sólo para los muy infectados.

- Pielotomía por cálculo renal. (Año 14 Diciembre 1927. no 17 pág. 215). Paciente de 33 años con cólicos nefríticos izquierdos desde los 12 años. Una radiografía que abarque los 2 riñones, como aconsejaba siempre Marion confirmó la litiasis piélica izquierda y otro muy pequeño en caliz medio derecho. Confirmada la función renal suficiente por la cromocistoscopia y la prueba de la fenolsulfoftaleína se interviene practicando una pielotomía posterior. Como enseñanza podemos exponer: Las radiografías deben abarcar todo el aparato urinario. El tratamiento expulsivo debe contemplar cálculos expulsable y el estado de la via excretora. La pielotomía es superior y sin riego comparda a la nefrolitotomía, que se reserva sólo para la litiasis coraliforme.

- Contratiempos de la urotropina. (Año 14. Diciembre 1927. n 17 pág. 217). La urotropina obra en virtud del formol que desprende en la orina ácida. Si la acidez es muy pronunciada y el epitelio urinario hipersensible los vapores de formol pueden congestionar total o parcialmente el urotelio.

- Un buen signo para diagnosticar el cólico nefrítico. Año 14. Diciembre 1927. n 17 pág. 217). En la mujer la litiasis ureteral espasmodiza y contrae el ureter que se puede palpar por vía vaginal como un cordón duro, tirante y algo doloroso.

- Prostatectomía perineal en un caso de fibroadenomatosis prostática supurada. (Año 20. Enero1934. no 23 pág. 317.) A raíz de una exploración por una micción frecuente por poliuria y practicar una electrocoagulación de unas placas leucoplásicas subcervicales en uretra posterior en un hombre de 45 años, a los 2 días, aparece una fiebre séptica y una retención de orina. Diagnosticado de un absceso prostático se practicó una perineotomía que dió paso a gran cantidad de pus. La exploración de la cavidad descubrió dos masas eferoidales que estaban sujetos por sus polos y que una flotaba dentro de la cavidad. Debido al estado grave y séptico del paciente se decidió no extirpar los adenomas y se dejó solo el drenaje. A los cuatro días se procedio a la prostatetomía siguiendo la técnica aconsejada por Gil Vernet, enucleando los adenomas por el pico, respetando la vejiga, el esfinter externo. Aprovecha el autor para glosar y recomendar la vía pe- 
rineal en la prostatectomía si se siguen las normas del doctor Gil Vernet.

- Reflexiones sobre la posibilidad de un nuevo tratamiento de la gonococia femenina basadas en el siguiente caso clínico. (Año 20. Noviembre 1934. no 24 pág. 321). El cambio de la acidez de una secreción vaginal condicionada por el bacilo de Döderlein, consiguió en una mujer joven el curar una rebelde gonococia. El autor se pregunta el alcance de esta observación.

\section{CURSOS PRÁCTICOS DE UROLOGÍA}

Para los que deseen especializarse. Dirigidos por el Dr. Serrallach (Año 2. Mayo 1914. no2. (pág. 32)

(Año 21 . Noviembre 1935. n²5. (pág. 344) Cuso 1935- 36. Acad. y Laborat. Cienc. Med. Catalunya.

\section{PUBLICACIONES RECIBIDAS}

(Año 2 . Mayo 1914. no2. (pág. 32).

- El exámen Pielo-Cisto-Radiografía. Su valor y aplicaciones a la Clínica. Por el Dr. Pérez del Yerro, y Mateo Milano, con 19 excelentes grabados. Madrid 1913.

- De la derivación temporal de la orina por vía perineal o hipogástroca en cirugía uretral, por el Dr. Barragan Madrid 1913.

- Genügtder N achweis von Tuberkelbazillen in dem durch Ureterenkatherismuns genoonneu Harn zu Diagnose der Nierentuberkulosien? por Kielienthner.Munchen.

- Consideraciones bacteriológicas y casuística clínica, por el Dr. Pérez Grande. Madrid.

- Revista Frenopática Española. Director: Dr. Rodriguez. 130- Barcelona (Año 12. Junio 1925, no 14 pág. 167-168).

- La clínica del Simpático y Parasimpático por el Dr. Antonio Guardia.

- Anestesia de los esplásquicos por el Dr. E. Ribas Isern.

- Un caso de Intoxicación por bismuto. por el Dr. Xavier Vilanova. Annales des Maldies Veneriennes no 1. 1923.
- Interpretaciones de las apendicitis=indicaciones operatorias. por el Dr. J. Marimón.

- Archivo de las enfermedades del corazón y de los vasos. T.III. Publicados por el Dr. Durán Arrom.

- Revista Española de Urología y Dermatología. Abril 1925." La radioterapia profunda en la hipertrofia prostática" por los Dres. Sala Parés y Pañella de Barcelona. (Año 16 Octubre 1929. no 19 pág. 256)

- La Renovación del organismo por el Dr. L. Dartigues. Doin. editor. Paris (Año 18 Noviembre 1931. no 21 pág. 287).

- Para cirugía por el Dr. Dartigué. Prefacio por el Prof. L. Faure.

\section{JUICIOS CRÍTICOS DE LA PRENSA MÉDICA}

- (Año 20. Noviembre 1934. no 24 pág. 321) sobre la Obra -"Interpretación Clínica de los Análisis de Orina, Diuresis y Micción"del Dr. N. Serrallach. (Año 3. Octubre 1916. n³ pág. 48).

- Revista de Medicina y Cirugía. no 4. Abril.- 1916. Barcelona. por el Dr, Baudilio Danés.

- Semana Médica de Buenos Aires. no $1155 .-1916$. por el Dr. Victor Delfino M.S.A.

- Sobre la Obra "Interpretación Clínica de los Análisis de Orina, Diuresis y Micción" del Dr. N. Serrallach. (Año 4. Junio 1917. n4 (pág.60).

- Anals de l'Acadèmia i Laboratori de Ciències Mèdiques de Catalunya. Any desè nº1. -Gener de 1916. por el Dr. R. Plá i Armengol.

- sobre la Obra "Interpretación Clínica de los Análisis de Orina, Diuresis y Micción. del Dr.N. Serrallach.

- Año Revista Médico Sanitaria.- Barcelona. Noviembre 1916 por el Dr. Ymbert (5. Febrero 1918. n5 pág. 70)

- Sobre la Obra "Interpretación Clínica de los Análisis de Orina, Diuresis y Micción del Dr. N. Serrallach.

- Revista Barcelonesa de Conocimientos Médicos. Barcelona Abril 1916. por el Dr. A. Costa 15. Febrero 1918. 5 pág. 70)

- Sobre la Obra "Interpretación Clínica de los Análisis de Orina, Diuresis y Micción. del Dr. N. Serra- 
llach. La Presse Mèdicale -Paris, 9 Juin 1919 por el Dr. Alfred Martinet (Año 6. Octubre 1919 n 7 pág. 84).

- Sobre la Obra "Interpretación Clínica de los Análisis de Orina, Diuresis y Micción. del Dr. N. Serrallach. Journal d'Urologie Médicale et Chirurgicale. Tome VIII, no 1-2. Paris Juillet 1919. por el Dr. SaintCéne Alfred Martinet (Año 6. Octubre 1919 n 7 pág. 84).

\section{AFORISMOS}

(Año 14 Diciembre 1927. no 17 pág. 219)

- La mayoría de las cistitis rebeldes son falsas cistitis, sostenidas por lesiones renales.

- Una falsa cistitis siempre tiene una capacidad vesical muy superior a la cantidad de orina que emite en cada micción.

- Las orinas purulentas que sedimentadas dejan un líquido de decantación turbio revelan una piuria pielo-renal; cuando es transparente la piuria es uretral y vesical.

- Detras de una cistitis rebelde se amaga una tuberculosis renal.

- Muchas falsas cistitis rebeldes provienen de una ureteropielietis, que un simple lavado de la pelvis renal por medio del cateterismo de los uréteres resuelve rápidamente.

- No todos los cólicos nefríticos son expresión de litiasis.

- Los cólicos nefríticos son debidos a pequeñas hidronefrosis pasajeras que pueden ser producidas lo mismo por un cálculo que por un espasmo del cuello pélvico, estenosis y acodaduras ureterales, nefroptosis e infecciones pieloureterales.

- El examen de la pelvis renal a la pantalla radioscópica, pieloscopía y pielografía permite descifrar el origen de muchos dolores renales.

- Muchas anurias son debidas a una inhibición renal por espasmo que cede al cateterismo ureteral.

- Las lesiones renales son indoloras y desde el momento que surgen algias renales, ello indica o que se trama una perinefritis o que se inflaman las vías urinarias colectoras altas.

- A la calculosis renal le acompaña siempre una hematuria microscópica.

\section{NOTA DE REUNIONES Y CONGRESOS.}

(Año 15 Octubre 1928. no 18 pág. 236).

- II Congreso hispano-portugués de urología. 10-12 Mayo 1928. Reportaje muy detallado de las sesiones, participación y trabajos presentados.

(Año 16 Octubre 1929. no 19 pág. 255)

- Sesión del día 4 de Junio de 1929 de la Sociedad
Catalana de Urología. Reportaje detallado de la sesion, participación y trabajos presentados.

(Año 18 Noviembre 1931. no 21 pág. 287).

- Fundación de la Sociedad Catalana de Urología. para trabajar por el fomento, progreso y personificación de la Urología Catalana. Elección de la Junta directiva Presidente: J. Mestres. Vicepresidente: N. Serrallach. Secretario: P. Gausa,...) e Información detallada de la primera sesión (6 de Junio 1931).

(Año 19 Enero 1933. no 22 pág. 304). - Sociedad Catalana de Urología. Renovación de los cargos vacantes de la Junta directiva: (Presidente: $N$. Serrallach. Vicepresidente: M. Breton. Secretario: F. Imbert...)

\section{NECROLÓGICAS}

- Dr. José Pagés y Puig. (Año 13. Marzo 1926, no 15 pág. 169). In memoriam de mi maestro.

- Dr Martin Parés i Parés (Año 18 Noviembre 1931. no 2 pág. 287).

- Dr. Emilio Sacanella (Año 18 Noviembre 1931. nº 21 pág. 287).

\section{AVISOS Y NOTICIAS}

- (Año 5. Septiembre 1918 no 6 pág. 76). Establecimiento de un Servicio gratuito de operaciones urológicas en la Clínica del Remei de San Gervasio, Barcelona, para clases modestas. Solo tendrán un dispendio de 5 ptas al día por gastos de clínica y asistencia médica. Es preciso la presentación de un documento suscrito por el médico o farmacéutico acreditando la pobreza del enfermo. Para más informes dirigirse a Dr. Serrallach. Pelayo 40. Barcelona. - (Año 12. Octubre 1924, no 13 pág. 167). Nos es grato comunicar que el joven Dr. D. Francisco Serrallach Juliá, que actualmente se encuentra en largo viaje por el extranjero para estudiar las distintas ramas que integran la Urología al lado de los maestros que más se han distinguido en el cultivo de las mismas, ha ingresado en nuestra redacción de Hojas Urológicas.

- (Año 19 Enero 1933. no 22 pág. 304). Inauguración del "Casal del Metge". Con gran solemnidad y con no menos entusiasmo tuvo lugar el mes pasado su inauguración; magnífica mansión de la clase médica catalana y templo augusto de la medicina de la tierra.

- (Año 20 Noviembre 1934. no 24. pág. 332). Después de laboriosas oposiciones el Dr. D. Francisco Serrallach Juliá ha obtenido la plaza de profesor auxiliar de la Cátedra de Urología de la Facultad de Medicina de Barcelona. 